
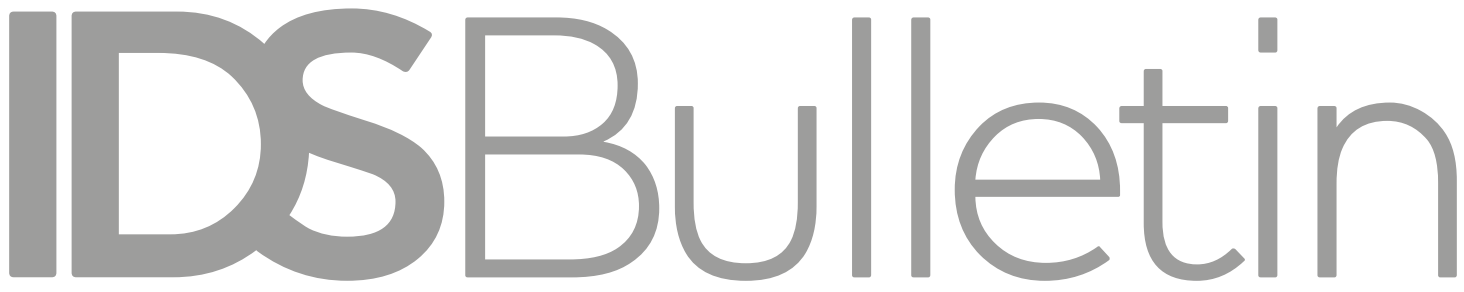

Transforming Development Knowledge

Volume 47 | Number 5 | November 2016

\title{
POWER, POVERTY AND INEQUALITY
}

\section{Editors Marjoke Oosterom and Patta Scott-Villiers}

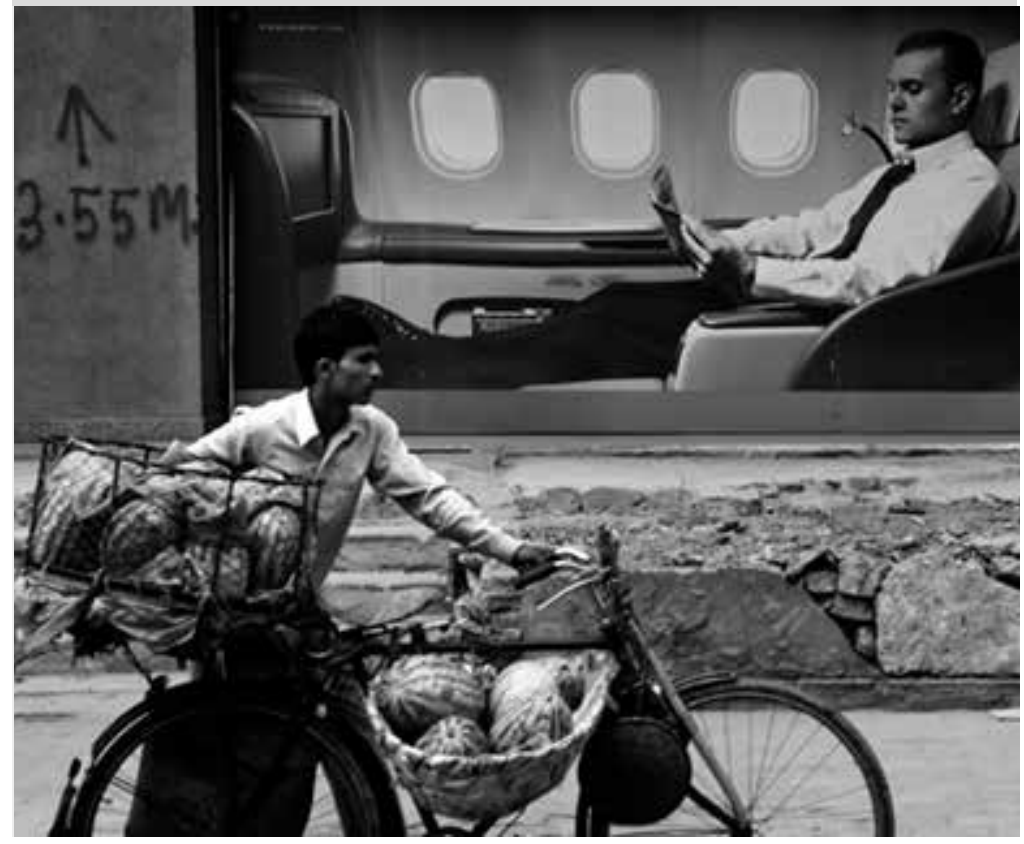


Notes on Contributors

Introduction: Power, Poverty and Inequality

Patta Scott-Villiers and Marjoke Oosterom

Inequality, Power and Participation - Revisiting the Links

John Gaventa and Bruno Martorano

Why Invisible Power and Structural Violence Persist in the Water Domain

Lyla Mehta

Inclusion as an Agenda for Transformative and Sustainable Change: Addressing Invisible Power through Reflective Practice

Jo Howard with Violeta Vajda

Intersectionality: A Key for Men to Break Out of the Patriarchal Prison?

Jerker Edström with Satish Kumar Singh and Thea Shahrokh

Towards a Pedagogy for the Powerful

Andrea Cornwall

Why Citizens Don't Engage - Power, Poverty and Civic Habitus

Jethro Pettit

Power and Empowerment Meet Resistance: A Critical, Action-Oriented Review of the Literature

Rosie McGee

Power in Practice: Bringing Understandings and Analysis of Power into

Development Action in Oxfam

Jo Rowlands

Glossary 


\title{
Power in Practice: Bringing Understandings and Analysis of Power into Development Action in Oxfam
}

\author{
Jo Rowlands
}

\begin{abstract}
Theorising about power has developed over the past decade in ways that support significantly more nuanced understanding and analysis; the implications of this for development practice are becoming better understood, but have yet to be systematically integrated in programme design and implementation. This article explores the process of strengthening and developing power analysis in the international non-governmental organisation (NGO), Oxfam. Some of the language is shifting, and power analysis has become a prerequisite for planning processes and is seen as a foundational skill. More programmes work intentionally with informal as well as formal power, and there is more willingness to engage with complexity. In practice, there is a hybrid approach to power analysis with multiple approaches in play. It is not easy to maintain and develop understandings in the face of constant changes, and the article explores some of the obstacles and issues that need further attention for theory to reach practice.
\end{abstract}

Keywords: power, power theory, power analysis, Oxfam.

\section{Introduction}

When I first started exploring power in relation to my work unpacking the concept of empowerment back in the 1990s (Rowlands 1997, 1995), the multifaceted nature of power quickly became evident. To make sense of 'empowerment', and in particular to explore ways in which women might grow their power, I felt it was essential to differentiate between forms of power and the ways in which the forms that are not zero-sum might effectively be thought about and cultivated. I worked with the now widely used ideas of power to, power with, power within and power over, and found them helpful in thinking through how initiatives towards women's empowerment might be approached (see also VeneKlasen and Miller 2007). Since then there has been significant further work by many people on power, and much more deliberate 
attention to bringing power analysis into the design of development programmes across a very wide range of activities and geographies.

Over the past 15 years I have been working with colleagues at Oxfam GB to explore how the organisation's work can be strengthened through better power analysis. For an organisation committed to reducing poverty and human suffering through a combination of humanitarian, long-term development and campaigning programmes, relations of power are a constant preoccupation for staff. The transformation of power relations such that women and men who are poor or marginalised are more able to make the choices that will improve their quality of life is a consistent ambition across the different elements of Oxfam's programmes. As an organisation with presence and activity, both directly and in partnership with other organisations, at all levels from local community to global, this means thinking about power in many ways. As Oxfam GB, a large organisation with considerable public recognition and as a member of a confederation with 17 members, two of which are based in the global South, ${ }^{1}$ we also grapple with our own power, how to use it and how to navigate its pitfalls. Like any organisation, Oxfam is not homogenous and this article exploring how these efforts have developed over time and what we have been learning as we keep trying to translate theory into practice through our programmes, rests on my personal observations, conversations and reflections, and my positioning within one of the global advisory teams.

When I first joined Oxfam, I found that the language of power was not particularly noticeable in the humanitarian and long-term development programming, though power analysis was well embedded within the campaigning teams. Here it was power analysis with a particular purpose of designing campaign strategy, and focused on understanding, in relation to the specific change sought, who would be making key decisions and how those people might be influenced. In particular, it emphasised understanding the identity and positioning of people who would support or block the change, and identifying undecided actors who might be open to persuasion. As such, it focused mostly on visible power, and to some extent on hidden power. ${ }^{2}$ On the back of this kind of analysis, some global campaigning such as that focused on debt cancellation and more and better aid (e.g. Drop the Debt, Education Now, and the Essential Services Campaign) was successful, to a degree, with some northern countries and global institutions through positive propositions. In contrast, what became a more defensive campaigning against the trade liberalisation agenda (e.g. Make Trade Fair and Trade Justice), whilst helping to bolster resistance to unfair rules amongst developing countries, has not yet resulted in significant policy or practice change. The underlying assumptions tended to be that having the right evidence, the right pressure on decision-makers and the right lobbying would lead to the desired change. Looking at campaigns that did not lead to real change on the ground, it became clear that more focus was needed at national level, for example. The assumptions about how change happened needed to involve a much wider range of actors 
in different parts of the system, and much more effectively link in with the actions of others at different levels. These analyses are still part of the power analysis lexicon in Oxfam, but over time we are seeing power explored in other ways. The leadership training for campaigners now includes a clear emphasis on thinking about how change happens, encouraging a much more nuanced approach that draws on systems thinking, incorporating consideration of how social norms and attitudes impact on policy decisions, and the various factors that prevent policies from being implemented. The power analysis framing began to include the ideas of the power cube (Gaventa 2006), looking at visible, hidden and invisible power at different levels and in different spaces, as well as the power within, power with, power to and power over framing I had used in my earlier research (Rowlands 1997, 1995). Some approaches to campaigning - most notably the 'We Can' campaign on violence against women - modelled a very different approach, growing the campaign from individual activism at household level upwards and outwards to communities and then national level. ${ }^{3}$

Gradually, the terminologies associated with power analysis and how change happens have found their way into key documents and processes, such as stakeholder analysis, that support staff with programme design and proposal development. For the first time in 2014 the document guiding strategy development and priorities at country level required all programmes to have both a theory of change and power analysis to guide programmatic choices. ${ }^{4}$ The language of changing attitudes and beliefs, part of the 'invisible power' of the power cube and closely associated with culture and norms, has also been used in Oxfam since the early 2000s. For a long time people knew this mattered but were not able to argue this aspect of the work to the top of priorities. Back then it failed, largely, to translate into significant changes in programme design and implementation. It is only recently that addressing these invisible forms of power has begun to be embedded in some of the programme methodologies through a deeper understanding of how poverty is underpinned by invisible forms of power, most notably in work addressing gender-based violence (GBV). Here, for example, we are seeing a shift to more focus on working with men and communities to explore how the culturally assigned value given to men's and women's activities and expectations of male and female behaviour limit everyone. It is probably no coincidence that this is the aspect of programming where more sophisticated power analysis has taken root, since there has been an understanding of gender relations as power relations, ${ }^{5}$ and of GBV as a controlling mechanism, for a long time. In addition, this connects with a focus on how gender intersects with other power relations based on social norms such as ethnicity, social class, and sexuality and age.

So the language is shifting, and some of the practice changes are following. This is partly, as mentioned earlier, because there has been a parallel move towards more systemic thinking and approaches that draw on understandings of complexity. ${ }^{6}$ This is associated with 
a move away from a focus on service delivery, which makes changes that people need, but on a very limited scale, towards changes that transform the institutional landscape and can reach far more people as a result. A more systemic approach encourages a focus on not only changing the policies and practices that emanate from institutions, but also changing the structures, processes and behaviours within them so they are more inclusive and open to redressing power imbalances between duty-bearers and rights-holders. Programmes can become more complex, working on several levels and informal as well as formal spaces, addressing a mix of policy, structure, process and behaviour. Or they can focus on one element, while concentrating on connecting more to the work of others. Either way, they require different skill sets from staff and partners. Power analysis helps us understand that changes that might be expected to follow logical pathways, such as increasing the availability of medicines in local clinics, get impeded by many factors - some are logistical problems, some are cash flow problems (probably relating to power struggles across different sectors within public budgets), some relate to who actually benefits from the system not working well (for instance, some private suppliers who may also be local power holders) and so on. Working more systemically also requires more varied work with multiple stakeholders positioned differently within existing power relations, leading to more of a focus on convening different actors, brokering relationships and proactively emphasising the inclusion of people who would otherwise be outside these spaces. If inclusion isn't possible, it may also require other forms of mobilisation such as citizen monitoring of budgets and expenditure. This can help facilitate change towards more equitable services and use of resources, reaching many more people and particularly those who would miss out under pre-existing arrangements. But to be effective and sustainable, power relations have to change. There are no simple solutions in this territory, and as an international non-governmental organisation (NGO) we need to include our own power as an organisation in the analysis, and for our staff to be able to understand and factor in their own positional and personal power in their relationships in the various spaces (including internally) within which we work.

Oxfam's ambition draws on its ability to link local action with national change and global reach, drawing on a wide network of actors as it does so. In this, Oxfam has travelled alongside other actors in the development sector towards 'thinking and working politically' and 'doing development differently', a journey which has reinforced the need to better understand power - although these debates, as well as the academic literature, are a long way removed from the realities of front-line communities, partner organisations and Oxfam staff in navigating the everyday complexities of the work. There is a significant challenge in applying theories of power in practice, so that they become embedded in ways of working, in relationships, and embodied in the people whose day-to-day action and behaviour can contribute to shifting power. In Oxfam the capacity for power analysis is now understood as one of the foundational skills that should underpin all programmes. 
In the rest of this article I will explore some of the issues I see in embedding and grounding power analysis into everyday programme activities, choices and methodologies.

\section{Changing how people think about power}

The dominant approaches to thinking about power in Oxfam, as elsewhere, interact closely with dominant thinking about how change happens. So, for example, where power is understood to rest with formal structures and political systems, change is seen as happening through policymaking, resource allocations, elite bargaining and formal political processes. This can imply a need for strong focus on policy change, often through campaigning and generating popular pressure. Oxfam has many examples of this approach in its history, from mobilising citizens around missing medicines in local clinics in Malawi to the people on the streets of the Make Poverty History campaign. This comes with a sense that if you get the policy change right, the change you seek will follow, if the resources and mechanisms of delivery are in place. This thinking has the attraction of indicating a route for taking any given change to scale. Thinking about power in this way can bring a bias towards formal structures and institutions, and political decision-making, because people feel they know what needs to be done and how to do that.

But this may not be enough. As has been seen many times, there are numerous instances of changes in policy, even where resources are allocated, not leading to the intended change. Often, failure of these approaches is ascribed to some combination of lack of political will and the effects of corruption - both of which indicate the need for a more complex understanding of power.

Another dominant approach to thinking about power, linked to thinking about how change happens, can be seen in what might be described as more bottom-up approaches. For example, where power is assumed to ultimately rest with people, a programme might seek to mobilise a population through building active citizenship and knowledge about rights so that local people will exert pressure for change from below; or it might seek to hold formal power holders to account for some aspect of their obligations to deliver rights, both of which can be seen in the Chukua Hatua programme in Tanzania. ${ }^{7}$ Again, Oxfam has taken these approaches in many places, such as in supporting many community score card, participatory budgeting or other social accountability initiatives. But doing this without also addressing the incentives keeping those in positions of power focused on the interests of other, often economic groups, can just lead to frustration, defeat or worse. Thinking about change and power through citizen activism coupled with empowering methodologies can contribute to significant change for individuals and groups, particularly in terms of self-perception and confidence. They do not, however, ensure transformation in power relations in at least the short term, even when they come together into movements, and therefore continued attention is needed to the institutionalised power dynamics and the incentives of the status quo. 
It is unlikely that many of the people designing programmes in Oxfam work with these clear-cut approaches to change any more, even if they have personal tendencies towards a particular perspective. The most recent generation of Oxfam country strategies demonstrated the beginnings of a move to a more complex picture of change processes, and power analysis was a required element in those plans, without prescribing how it was to be done. In practice, some of the resulting power analysis was superficial; some was done more comprehensively at the level of context analysis, but then not actively used to feed through into thematic and strategic choices; but some was done well, leading to redesign and refocusing of content, approach and/or entry points and new approaches to partnership.

I would also say it is less common now for power analysis to focus only on formal and institutionalised power; there is much more discussion in Oxfam programmes of traditional/customary/informal forms of visible power than was common a decade ago. A newly designed Food Security and Resilience programme in South Sudan, for example, intentionally works with local government actors as well as traditional leaders and community members to shift dynamics of power by changing the expectations they have of each other. The accompanying risk analysis is more likely to anticipate how hidden power might interact with the programme. And a number of programmes are very deliberately focusing on invisible power, looking at how culture and public opinion can change, and at how to support changes in the ideas and beliefs that hold particular inequalities or injustices in place. These include programmes working to shift the norms that prevent women's full participation in economic and public life. ${ }^{8}$ It still remains a challenge to ensure that the analysis of power informing programme design and the strategic choices made by teams to focus their work is sufficiently robust and nuanced to make the best use of resources. And it is still a challenge to ensure that Oxfam's own power is factored into the thinking, both constructively, such as using its convening power to bring people together who otherwise might not collaborate, or in mitigating potential negative effects such as imposing bureaucratic requirements on partners that make it hard for them to stay focused on their own goals. But increasingly, Oxfam programmes are looking at ways to work on how the invisible power of norms, attitudes and beliefs affect whether particular policy or practice changes get made, have traction and lead to real change.

So I see progress in a journey from simple to complex, with an increasing willingness and even requirement to dig much deeper into the messy realities of how change happens, even, or perhaps especially, if the resulting programmes focus on simple ideas, or on continuing with familiar things that are known to work. This requires sophisticated thinking about power. And more nuanced power analysis supports more deeply drawn ideas about how change happens, opening up a new range of options for action, whether by Oxfam or by others. In addition, given the complexities, it will rarely be the case that the 
analysis is complete or perfect. You often don't know how power really works in reality until you fully engage with it, so if combined with regular updating, reflection and review, good power analysis supports more agile, responsive and ultimately relevant initiatives. It is essential that space be built into programme plans to allow a regular passage round the loop of theory to practice and back again, to support learning from action and action from learning.

\section{Hybrid power analysis}

Various initiatives, including the Oxfam International (OI) Campaigns and Advocacy Leadership Programme, the 'National Influencing Guidelines', and a Gender and Power course under development by the OI gender team that unpacks the relationship between gender and power linking gender analysis frameworks ${ }^{9}$ with the forms and expressions of power, all indicate that Oxfam is absorbing ideas from several sources to combine into a hybrid approach to power analysis. The early dominance of the campaigning power analysis described earlier has gradually incorporated the idea of looking not just at the structures around which power organises but the forms it takes (visible, hidden, invisible), how it is expressed (power within, with, to and over), who the actors are, how it is gendered, how it works in different spaces, at different levels and how they interconnect. There is also a continuing adherence to using some of the more conventional political economy analysis as part of the mix, as well as complexity and systems thinking. ${ }^{10}$ This allows country offices to try things out and adapt, drawing on learning and reflection to select what works best in their context.

There has been no formalised attempt as I write to 'roll out' a standard approach to power analysis. Instead, a number of individuals, ${ }^{11}$ myself included, have been sharing the ideas through the channels available to us, including through workshops and training opportunities on a wide range of subjects, through work to support colleagues with developing theories of change, through countless conversations, through programme support visits and, in my case, through the many induction meetings I have had with new staff over a period of about eight years, most of whom got a mini power analysis seminar. In effect, the approach has been to spread power analysis 'virally'. This has allowed individuals and teams to take their own approach, which has been useful in some respects in allowing for context-specific application and experimentation, but also leading to inconsistent application and gaps in application where there was no one confident enough to give it a try.

\section{Oxfam's power analysis ambition}

The more Oxfam works through a systems lens, the more we are faced with difficult choices because of the twin increasing pressures of chronic emergencies on the one hand and our resource constraints on the other, and the more multi-polar the world is becoming, the more we need power analysis to inform context analysis and decision-making. At a country level, political dynamics are more and more critical to the organisation's effectiveness and ability to build the relationships we 
need to support the work on the ground, and connect that as needed to other levels. Our staff and the partner organisations we work with are navigating complex dynamics that are shifting all the time. Increasingly, Oxfam is navigating a closing operating space for civil society as an international NGO, as are our civil society partners and allies. We need to be more agile and confident to adapt. An increasing proportion of the organisation's work is in contexts where formal and informal power dynamics combine to create conditions of fragility and violent conflict. Getting a better understanding of power in the range of ways it manifests is correspondingly urgent.

Programme design is often the product of compromises between the needs in the context and the priorities of Oxfam, its partners and the providers of funding. Better power analysis - of the context and also relating to the power dynamics within partnerships, consortia and within Oxfam itself, can support the process of programme design by anticipating and mitigating some of the compromises. It can help us be more conflict sensitive and more confident of not inadvertently doing harm. Thorough power analysis can help us see more clearly the choices we make, as well as help us be more imaginative in our identification of and approaches to partnerships, alliances and other key relationships - both in terms of who we work with and how we work. For example, Oxfam's expanding engagement with young people requires very different approaches and methodologies than we have used up till now; and the wide range of work engaging the private sector, extending from micro-entrepreneurs and smallholder farmers to large corporate entities, requires constant and very different attention to power relations than hitherto. A greater fluency in power analysis would also help the organisation as it adjusts to shifts in power that emerge from partners and allies using their own power in ways which are disturbing to Oxfam's assumptions, expectations and familiar ways of working. So, for instance, when a partner who has received our support for some time begins to occupy a national or global space that Oxfam is more used to occupying itself, even if this is exactly the change that was intended, it nonetheless indicates a shift of power dynamics and the need for fresh thinking.

I would add that despite many years working with participatory and rights-based approaches, there is an ongoing need to develop stronger understanding across the spectrum of Oxfam regarding the ways in which the methods used, the relationships built, the behaviours and the choices made by individuals in different positions reflect power dynamics, both within the organisation and in relation to other actors. This is by no means all negative, and there are many examples of deliberate use of the power of Oxfam, for instance to enable others to access national or global spaces. But this is not an area where knowledge and understanding can be taken for granted. Inevitable staff turnover can mean that hard-won learning about how to work in inclusive and context-sensitive ways evaporates. A programme designed by someone with a deep understanding of power in the context may be 
implemented by someone who does not have that understanding and therefore would not realise the implications of making changes. It needs constant refreshing and constant visibility.

\section{Addressing the obstacles}

Power analysis, applied in real programmes to understand real contexts, and to help identify effective approaches to change in complex, dynamic environments, is an essential part of Oxfam's work. It helps the organisation focus on the right impacts and outcomes, keep its work relevant, and stay focused on its priorities. At the same time, there are many obstacles to it being used consistently and effectively, whether by staff, partners or communities. These can be clustered into five categories:

Content: The language of power analysis can be quite obscure and/ or unnecessarily academic. It can also be quite culture-specific (e.g. talking about the invisible power embedded in 'work-life balance' in a context where the distinction between work and personal life has little meaning). And the competing frames for power analysis can be confusing, leaving people unconfident and not sure where to start. It is important to communicate that although power is multifaceted, it is in no way mysterious and can be explored and made sense of. Power is around us everywhere, we all experience it in multiple ways even if we never think about it. It is useful to ask questions about existing work, how it engages with what kinds of power, what it avoids, where opportunities might be being missed because of assumptions made about who the programme can or can't work with and why. Different people are comfortable with different ways of thinking about power; sometimes people think 'their' way is the right way: it is useful to explore less familiar ones that help challenge the invisible power that sits in people's habitual ways of thinking and behaving.

Skills: Some people seem to have the knack of power analysis without even thinking about it much. Such people read the context, connect with diverse sources of information and seem almost intuitively able to keep a finger on a multifaceted pulse in terms of the political context. Such people are not commonly found in development management, though sometimes they are found in policy roles. Even they often have 'blind spots', perhaps not understanding the role of invisible power, or that it is possible to build some kinds of power.

However, few people feel confident to just do power analysis. There is a strong temptation to bring in 'experts' to do it for you; this can be a quick fix, but doesn't leave a team any better able to do power analysis for themselves, and would miss the opportunity to develop the thinking skills and habits that iterated power analysis can bring. To do power analysis requires thought process as well as data. Strong power analysis generally needs to draw on knowledge from diverse sources, and if that involves people, there also needs to be a managed group process. It is certainly not necessary for everyone involved to be familiar with the theoretical literature, but a good process 
facilitator and one person confident with power analysis (who could perhaps be the same person) will be able to make sure questions are asked using language and images that will work for the specific participants, to make tacit knowledge explicit, to help the group build a composite picture and identify knowledge gaps. With good facilitation it is possible to build a complex picture and then draw out clear, straightforward implications for choices, actions, approaches, etc. In addition, it is very helpful to be able to reflect with others, and to invite peer support from critical friends.

Responsibility and accountability: In an organisation like Oxfam, power analysis is one of those areas that usually falls across several areas of responsibility and is therefore vulnerable to having no one actually accountable for ensuring it happens. Ideally, it becomes so much part of the everyday way of doing things that it happens automatically but to reach that point, a degree of encouragement may be needed. In Oxfam, for example, that might mean decision-makers requiring a clear power analysis to defined standards as part of every funding proposal above a certain minimum level. The internal division of labour between different teams in Oxfam can also make it difficult to get sufficient diversity of knowledge and perspective if teams are undertaking separate power analyses. So leadership with clear expectations, vision and motivation will be important in doing power analysis well.

Application: Power analysis is most usefully iterative and ongoing, used to identify priorities, partnerships and alliances, to guide a range of relationships, to inform linkages between work at different levels, to ensure conflict and gender sensitivity and therefore to inform choices of methodology and approach. In practice, it should help identify whose voices need to be included in a programme, who needs to be leading and how those can be achieved. In itself, power analysis provides excellent opportunities for inclusive process that bring diverse perspectives and deep local knowledge into view. So it needs to be built into planning cycles, adequately resourced and monitored.

Time: Heavy workloads, competing priorities, multiple deadlines and very ambitious programmes mean that it can be hard to carve out space for analysis and reflection. Space for learning, often closely linked with monitoring and evaluation, is increasingly being built into programme plans, and power analysis lends itself easily to these spaces. They can be good moments for updating and noticing changes. Learning needs to be incentivised, with clear commitment and drive from senior management to encourage and allow staff to make this space.

\section{Conclusion}

Power dynamics are everywhere, ubiquitous, complex and still only partially understood. This is as true in international development as in other spheres of human activity. The aid and development sectors are in a period of change and questioning, and under pressure to deliver in 
new ways. Many people's lives have improved significantly, but the power dynamics that maintain poverty and inequality are clearly still firmly in place. There is significant potential to support a new generation of locally appropriate development work, that makes the most of potential synergies between actors, that transforms power relations in favour of those who currently get a poor deal, and that is able to take advantage of unexpected opportunities and moments of upheaval (critical junctures) when they occur. I am greatly encouraged by the way that voices have been emerging in the sector that encourage a wide range of actors to base their work on a deeper understanding of real power dynamics in real places (what is, rather than what should be), guided by local knowledge as well as specialist expertise. To do this well there needs to be a step-change in the understanding of power and how change happens. There has been a focus on 'locally driven', or 'going with the grain' approaches which has been refreshing on the one hand, in moving away from top-down imposition and conditionality; but on the other hand, if the power analysis is not robust enough and the approaches used do not deliberately compensate, there is a serious danger of reinforcing power imbalances that really need to be transformed.

It is encouraging that some funding bodies are beginning to expect more adaptive programming that is designed to handle moments of crisis or turmoil and be prepared to take opportunities that arise. Organisations like Oxfam wanting to work in these new ways will need to become more agile in reading the context as it shifts and changes, and our abilities to do high robust power analysis will be essential, not only in making that possible, but also in managing the inevitable risks to ourselves, our partners and the people on whose behalf we do what we do.

In Oxfam, we have come a long way towards getting power analysis embedded into the everyday thinking and practice of the range of people who could make good use of it, but we have not yet reached the point where it stops being something daunting, separate or added on. We do not yet consistently include ourselves in our power analyses and allow that to inform how we work. We are part of the way on a journey from power analysis being the territory of a few 'experts', towards building it as a common core capacity in the sector that people expect to develop and in which they are fluent.

\section{Notes}

* Oxfam GB unless it's clear I refer to the Oxfam International (OI) confederation.

1 With two more in the process of moving towards membership.

2 My use of language; this is not the way it was described at the time (September 2016).

3 http://policy-practice.oxfam.org.uk/publications/the-we-cancampaign-in-south-asia-338472

4 'Developing the Oxfam Country Strategy: Guidelines for the Use of Country Teams as they Review their JCAS and Develop the Oxfam Country Strategy', internal publication, Oxfam, 2014. 
5 Arguably, feminists have been discussing power since Simone de Beauvoir and before. See for example, Hartsock (1983).

6 http://policy-practice.oxfam.org.uk/publications/systems-thinkingan-introduction-for-oxfam-programme-staff-579896

7 http://policy-practice.oxfam.org.uk/publications/the-chukua-hatuaaccountability-programme-tanzania-338436

8 See, for example, We Care: http://policy-practice.oxfam.org.uk/ publications/oxfams-we-care-initiative-an-overview-555515

9 www.genderatwork.org/OurWork/OurApproach/GWFramework. aspx

10 http://policy-practice.oxfam.org.uk/publications/systems-thinkingan-introduction-for-oxfam-programme-staff-579896 and animation: http://policy-practice.oxfam.org.uk/blog/2015/10/making-systemsthinking-real

11 I've particularly appreciated conversations with Richard English, Duncan Green, Jemma Stringer, Bridget Snell and Irene Guijt.

\section{References}

Gaventa, J. (2006) 'Finding the Spaces for Change: A Power Analysis', IDS Bulletin 37.6 23-33, http://bulletin.ids.ac.uk/idsbo/issue/ view/64 and www.powercube.net/wp-content/uploads/2009/12/ finding_spaces_for_change.pdf (accessed 18 August 2016)

Hartsock, Nancy (1983) Money, Sex, and Power: Toward a Feminist Historical Materialism, New York NY: Longman

Rowlands, J. (1997) Questioning Empowerment: Working with Women in Honduras, Oxford: Oxfam GB

Rowlands, J. (1995) 'Empowerment Examined', Development in Practice 5.2: $101-7$

VeneKlasen, L. and Miller, V. (2007) A New Weave of People, Power and Politics, Just Associates, www.justassociates.org/en/resources/newweave-power-people-politics-action-guide-advocacy-and-citizenparticipation (accessed 3 September 2016) 